\title{
Mitarbeiterinnen und Mitarbeiter dieses Heftes
}

Dr. Guido Bee ist seit 2005 Referent an der Deutschen Nationalbibliothek in Frankfurt am Main.

Florian Bock, M.A., ist wissenschaftlicher Mitarbeiter am Lehrstuhl für Kirchengeschichte des Mittelalters und der Neuzeit der Katholisch-Theologischen Fakultät der Ruhr-Universität Bochum.

Prof. Ernst Elitz moderierte „Kennzeichen D“ und „heute journal“ beim ZDF und war Fernseh-Chefredakteur des Süddeutschen Rundfunks. Von 1994 bis März 2009 war Elitz Intendant des Deutschlandradios.

Dr. Stephan Kronenburg ist Pressesprecher und Leiter der Bischöflichen Pressestelle des Bistums Trier.

Prof. Dr. Horst Pöttker lehrt seit 1996 als Professor am Institut für Journalistik der Universität Dortmund. Zuvor lehrte und forschte er an den Universitäten in Siegen und Leipzig.

Dr. Eckart Roloff war Referent im Bundespresseamt und leitete von 1988 bis 2007 das Ressort „Wissenschaft und Praxis“ beim „Rheinischen Merkur" in Bonn.

Prof. Dr. em. Michael Schmolke lehrte bis 2002 Publizistik und Kommunikationswissenschaft in Salzburg. Er ist Mitherausgeber von Communicatio Socialis.

Melanie Verhounik, Diplom-Journalistin, M.A., ist wissenschaftliche Mitarbeiterin am Lehrstuhl für Journalistik I der Katholischen Universität Eichstätt-Ingolstadt. 